conducted for various reasons, mostly time consuming and costly. This study aimed to shorten the fit testing procedures by improving the instrumental settings, sampling system design, and data analysis protocols.

Methods Experiments of fit factor measurements were divided into two parts: constant flow and cyclic flow using a breathing simulator. To simulate leakage, capillaries $(10 \mathrm{~mm}$ in length, diameter $1.0-1.5 \mathrm{~mm}$ ) were used to insert on N95 and N100 filtering facepieces. The ratio of total to leak flow was considered the 'true fit factor, FFt'. Flow rates ranging from $5-50 \mathrm{~L} / \mathrm{min}$ were employed to study the flow dependency. The measured fit factors were determined by concurrent particle concentration measured by a Portacount and a OPS 3330. The default $1.7 \mathrm{~m}$ sampling tube was used to connect filtering facepiece to the aerosol instruments. In addition, the effects of breathing pattern (tidal volume: $0.5-1 \mathrm{~L}$, frequency: 5-20 times/min) and lung deposition (with/without HEPA filter behind the respirator) on in-mask particle concentration during fit testing were analysed, to explore the minimal sampling time that approximated the FFt.

Results The particle measurement response times for Portacount and OPS were approximately 5 and $2 \mathrm{~s}$, respectively. For P100 respirators, most measured fit factors were close to the FFt. Whereas, there was an underestimation while using N95 respirator due to filter penetration. Therefore, N95-companion was necessary while testing N95 respirator. For the cyclic flow tests, the fit factor was overestimated because the sampling tube was connected onto the facepiece where filtered air was partly sampled. The higher the breathing flow rate, the more the fit factor was overestimated. On the other hand, the measured fit factor would be close to the FFt when using the highest concentration during a breathing cycle (FFmin). In theory, it could be decided in only one breathing cycle.

Conclusion With improved design in instrumental setting and operating procedures, a fit test for an individual exercise would take approximately only $12 \mathrm{~s}$. Therefore, the whole fit testing process could be shortened from 7.5 to about $3 \mathrm{~min}$.

\section{DEVELOPMENT OF A COOL AND CLEAN AIR MOTORCYCLE HELMETS}

${ }^{1} \mathrm{AL}$ Jian*, ${ }^{1} \mathrm{SH}$ Huang, ${ }^{2} \mathrm{YM}$ Kuo, ${ }^{1} \mathrm{CW}$ Lin, ${ }^{1} \mathrm{WC}$ Lee, ${ }^{1} \mathrm{CC}$ Chen. ${ }^{1}$ National Taiwan University, Taipei, Taiwan; ${ }^{2}$ Chung Hwa University of Medical Technology, Tainan, Taiwan

\subsection{6/oemed-2018-ICOHabstracts.577}

Introduction Motorcyclists could be exposed to high $\mathrm{PM}_{2.5}$ up to $460 \mu \mathrm{g} / \mathrm{m}^{3}$. The aim of this work was to develop a full faced helmet $(\mathrm{FFH})$ that provides clean air and cool temperature inside the helmet to reduce particulate exposure and increase comfort for motorcyclists.

Methods A commercial FFH was modified to generate cool and clean air in a way similar to the powered-air-purified-respirator, commonly used in industrial settings. Three different clean air supply locations (A: upper rear of the head, B: zygomatic side, and C: lower chin) were applied to investigate the location effect. A small wind tunnel was used to simulate the turbulence that motorcyclists might encounter while riding on the road. The operating parameters included: the supply air flow rate to the helmet $\left(\mathrm{Q}_{\mathrm{s}}\right)$, the velocity in the wind tunnel $\left(\mathrm{U}_{0}\right)$ and breathing flow rate which is a combination of tidal volume and breathing frequency. To minimise infiltration of aerosol outside the helmet into the breathing zone, the FFH was tightly surrounded with a neckerchief made of different materials. The stiffness of the neckerchief was measured by using a $45^{\circ}$ angled Cantilever. A condensation particle counter was used to measure particle number concentrations both inside and outside the FFH, to calculate the protection factor, PF.

Results The PF of the FFH increased with increasing $Q_{s}$, but decreased with increasing wind speed and breathing flow rate. At breathing flow rate of $7.5 \mathrm{~L} / \mathrm{min}$ with the $\mathrm{FFH}$ sealed using neckerchief, PF increased from 1 to 900 as Qs increased from 0 to $50 \mathrm{~L} / \mathrm{min}$ under calm air condition, with air supply through location A. Meanwhile, the PF decreased from 900 to 3 when wind velocity increased from calm air to $10 \mathrm{~m} / \mathrm{s}$. The PF increased significantly when the FFH was sealed with a neckerchief made of soft shell (stiffness $19.2 \mathrm{~mm}, 28 \mathrm{~cm}$ long). In addition, the temperature on the top of head decreased with increasing supply air flow.

Discussion Applying a higher $\mathrm{Q}_{\mathrm{s}}$ up to $100 \mathrm{~L} / \mathrm{min}$ is necessary, not only to maintain a positive pressure inside the helmet but also to decrease the concentration of carbon dioxide exhaled by the wearer. The use of the soft shell neckerchief is also critical to reduce the infiltration due to external turbulence.

\section{SHIFT OF AEROSOL PENETRATION IN SIZE-SELECTIVE CYCLONE SAMPLERS}

${ }^{1} \mathrm{TJ}$ Chen, ${ }^{1} \mathrm{SH}$ Huang, ${ }^{1} \mathrm{CW}$ Lin, ${ }^{2} \mathrm{YM}$ Kuo, ${ }^{1} \mathrm{CC}$ Chen. ${ }^{1}$ National Taiwan University, Taipei, Taiwan; ${ }^{2}$ Chung Hwa University of Medical Technology, Tainan, Taiwan

\subsection{6/oemed-2018-ICOHabstracts.578}

Introduction Size-selective aerosol samplers are used to assess the health effect, because the retention of deposited particles in the respiratory tract is strongly size dependent. The main objective of this work is to examine the particle loading effects on PM2.5 cyclone samplers.

Methods In this work, five PM2.5 cyclones of different body diameters $(9.3-35.6 \mathrm{~mm})$, derived from the BGI VSCC, were designed and fabricated to investigate the effects of particle loading. An ultrasonic atomizing nozzle was used to generate micro-meter-sized potassium sodium tartrate (PST) particles and Sodium chloride $(\mathrm{NaCl})$ particles as solid challenge aerosols, and di-ethyl-hexyl-sebacate (DEHS) particles as liquid challenge particles. Aerosol number size distributions and concentrations, both upstream and downstream of the cyclones, were measured using an aerodynamic particle sizer. In addition to the cyclone body diameter, other parameters investigated in this work included: challenge aerosol size distribution, chamber humidity, and the material of the cyclone.

Results The PM2.5 cyclones could be used to sample liquid particles without any bias, because the deposited liquid aerosols dripped down and did not accumulate on the inner wall of the cyclone. However, when challenged with solid particles, the deposited and accumulated aerosols on the wall reduced the aerosol penetration, and changed the curve to be less sharp. The extent of underestimation was affected by many parameters, such as challenge aerosol size distribution, humidity, test agent, and the elastic properties of the cyclone and the test agent. On average, there was an underestimation of $20 \%$ of $2.5 \mu \mathrm{m}$ aerosol penetration when challenged with PST particles, regardless of cyclone body size. This suggested that cyclones might not be ideal for sampling solid particles.

Discussion Cyclone samplers currently used for size-selective sampling are likely subject to aerosol loading effect, and resulted in underestimation of the PM2.5 measurements. The use of virtual cyclone or wet cyclone might solve parts of the problem. 


\section{Infectious Occupational Agents}

\section{HEALTH RISK MANAGEMENT: APPRAISAL OF TWO MCP MODELS FOR NON-IMMUNE EXPATRIATE WORKERS WITHIN NIGERIA'S OIL INDUSTRY}

Ol Ajayi*. Medbury Medical Services, Lagos, Nigeria

\subsection{6/oemed-2018-ICOHabstracts.579}

Introduction Malaria remains a major occupational health concern accounting for several deaths per year and numerous lost work days among expatriate population, working and living in high malarious areas. Approximately $1 \%$ of all non-immune travellers who acquire $P$. falciparum infection die. Nigeria is a malaria endemic country with high transmission throughout the year. Employers within the oil industry usually adopt a malaria control program (MCP) which in generic terms consists of awareness, bite prevention, use of chemoprophylaxis and early diagnosis and treatment. It is clear that no single approach will sufficiently reduce this risk.

Methods Primary data was gathered through self-administered anonymised questionnaires to 35 non-immune expatriate respondents attending a clinic in Lagos. The questionnaire, completed at spot, sought to gather information on awareness and uptake of various employers' corporate malaria control programs - chemoprophylaxis use vs CMK/SBET approach.

Results Awareness to the malaria risk is high in the population at risk and this increased risk perception is significantly associated with risk-averse behaviours $(\chi 2=6.13$, CI 99\%). Take-up of chemoprophylaxis (91\%) while at work is encouraging as is compliance, post-travel. $60 \%$ of respondents that use chemoprophylaxis also carry Curative Malaria Kits (CMK). However, this risk perception did not seem to be significantly associated with acceptance of employer's policy contractually obligating use of chemoprophylaxis. $\left(\chi^{2}=0.73\right.$, CI $\left.50 \%\right)$.

Conclusion The most crucial aspect of any MCP is awareness. When non-immune employees are properly aware of the malarial risk, they are normally motivated to take responsibility for their own health and safety, and exhibit this motivation by demonstrating flourishing positive attitudes to preventative measures and advice given by employers. The study shows that although non-immune employees seem to be aware of the malarial risk, gaps in knowledge still exist. Long-term occupational travellers, rotational and offshore workers present some of the biggest challenge to the oil industry's effort at controlling malaria.

\section{MICROBIOLOGICAL AIR QUALITY ASSESSMENT OF PUBLIC HEALTH HOSPITALS, SOUTH AFRICA}

\begin{abstract}
1,2Tanusha S Singh, 1,2Onnicah D Matuka, 'Lufuno Muleba, 'Thabang Duba, 'Zethembiso Ngcobo, ${ }^{1}$ Tebogo Nthoke. ${ }^{1}$ National Institute for Occupational Health, National Health Laboratory Services, Johannesburg, South Africa; ${ }^{2}$ Department of Clinical Microbiology and Infectious Diseases, University of Witwatersrand, Johannesburg, South Africa
\end{abstract}

\subsection{6/oemed-2018-ICOHabstracts.580}

Introduction Bioaerosols and infectious patients in various departments within health facilities can be a risk of airborne infections. Concentration profiles of airborne bacteria including Mycobacterium tuberculosis (MTB) in hospitals have not been well characterised. This study assessed the levels of airborne bacteria and evaluated whether carbon dioxide $\left(\mathrm{CO}_{2}\right)$ could be an indicator of airborne bacterial concentration.

Methods A cross-sectional study was conducted at four public sector hospitals in South Africa, two with ultraviolet germicidal irradiation (UVGI) fixtures (A and D) and two without (B and $\mathrm{C}$ ). Risk areas included respiratory isolation rooms, TB wards, respiratory wards, general medical wards, outpatient consulting rooms and waiting areas. Air samples $(n=316$, $\mathrm{A}=106, \mathrm{~B}=30, \mathrm{C}=58, \mathrm{D}=122$ ) were collected in the morning and afternoon using the MAS-100 sampler. Personal (4 1/s) and stationary $(20 \mathrm{l} / \mathrm{s})$ airborne TB samples were collected and quantified by real-time qPCR. Environmental parameters (temperature, relative humidity $(\% \mathrm{RH})$, air velocity and $\left.\mathrm{CO}_{2}\right)$ were also measured. The data was analysed using Stata version 11.1.

Results The results revealed differences $(p<0.05)$ in air quality within and between hospitals. The average bacterial levels ranged from 20-1380 cfu/ $\mathrm{m}^{3}$, with hospital $\mathrm{C}$ having the highest average counts $\left(611 \mathrm{cfu} / \mathrm{m}^{3}\right)$ followed by hospital B with $365 \mathrm{cfu} / \mathrm{m}^{3}$. Detectable airborne TB was reported in the waiting area of hospital B. Hospitals with UVGI fixtures had significantly $(\mathrm{p}=0.0001)$ lower airborne microbial loads (181 $\left.\mathrm{cfu} / \mathrm{m}^{3}\right)$ than those without $\left(528 \mathrm{cfu} / \mathrm{m}^{3}\right)$. The Kruskal Wallis test showed no bacterial count variability over a three day period or between morning and afternoon. A meaningful correlation $(\mathrm{r}=0.51, \mathrm{p}<0.05)$ was found between airborne microbial levels and $\mathrm{CO}_{2}$ levels (401-2398 ppm).

Conclusion $\mathrm{CO}_{2}$ may be a predictor of microbial air quality however low bacterial counts may contain pathogens which may cause infection. Non-TB areas such as waiting areas pose a risk of exposure for health workers.

\section{OCCUPATIONAL HEALTH ASPECTS OF EMERGING INFECTIONS - THE EXPERIENCE FROM DEVELOPING COUNTRIES}

David SQ Koh*. Universiti Brunei Darussalam, Brunei Darussalam

\subsection{6/oemed-2018-ICOHabstracts.581}

Aim of special session This session will cover occupational health aspects of emerging infections among healthcare workers and other occupational groups in developing countries. Presenters from Brunei, Singapore, Thailand and the United Arab Emirates will share their firsthand and contemporary experiences on the subject, and the strategies to manage this important issue in occupational health.

${ }^{1}$ Dr Lim John Wah, ${ }^{2}$ Dr Adul Bandhukul, ${ }^{3}$ Dr Pg Khalifah Ismail

${ }^{1}$ Khoo Teck Puat Hospital, Singapore

${ }^{2}$ Nopparat Rajathanee Hospital, Bangkok, Thailand

${ }^{3}$ Ministry of Health, Brunei Darussalam

\section{9a FLU VACCINATION FOR HEALTH CARE WORKERS - WHY AND WHY NOT?}

John Wah Lim. Khoo Teck Puat Hospital, Singapore

\subsection{6/oemed-2018-ICOHabstracts.582}

Influenza is a common infection affecting the general population. It has various implications on both patients and health care workers (HCWs). HCWs can acquire influenza from the 